\title{
Primary carrier sites of group B streptococci in pregnant women correlated with serotype distributions and maternal parity
}

\author{
AKMS ISLAM \\ From the Department of Medical Microbiology and Public Health Laboratory, \\ Whipps Cross Hospital, London E11 1NR, UK
}

SUMMARY Perianal, perineal, vulval, and vaginal swabs from women attending an antenatal clinic were quantitatively cultured for group B streptococci using Islam's medium. The isolation rates from the four sites were very similar with an overall carriage rate of $21 \%$. The findings suggest that the type II strains, a faecal flora, probably colonise the perianal site from a faecal source, and that the type III strains colonise primarily the genital site and then spread to the perineoperianal region. The type I strains did not conform to any pattern, suggesting a possible secondary involvement of these sites from another primary source. The types $I, R, X$, and non-typable isolates were almost exclusively isolated from primigravidae and second gravidae; the type III strains were conspicuously absent in 47 primigravidae. The primigravidae and second gravidae women consistently had high colony counts.

The distributions of the various serotypes of group B streptococcal isolates in pregnant women appear to be almost identical, ${ }^{1}$ but the predominance of types I and III in group B streptococcal neonatal disease (unpublished, PHLS Commun Dis Rep) is unexplained. In a recent study, Islam and Thomas ${ }^{2}$ found only $6 \%$ faecal carriage rates of group B streptococci in women, all type II strains, compared to $27 \%$ and $17 \%$ rectal and vaginal carriage rates, respectively. These findings suggest that only a proportion of group B streptococcal isolates are true gut flora, and that the gastrointestinal tract, which has recently been implicated as a major reservoir of group B streptococcal infections, ${ }^{3}$ is unlikely to be a significant source of neonatal infections. This implies that types I and III group B streptococci may have other primary source(s), and this has important epidemiological implications.

In this study the rates of colonisation and viable group B streptococcal counts in perianal, perineal, vulval, and low vaginal sites in pregnant women were compared. It was hoped that qualitative and/or quantitative differences in the recovery of various serotypes might indicate their respective primary carrier sites.

Accepted for publication 19 June 1980

\section{Material and methods}

Perianal, perineal (the area between the posterior fourchetteand the outer margin of the perianal region), and vulval swabs were taken from 101 consecutive women attending the antenatal clinic of Whipps Cross Hospital; low vaginal swabs from 41 patients were included at a later stage of the study. All swabs were transferred immediately to Stuart's transport medium and were processed and cultured within $\frac{1}{2}-2$ hours of collection.

Islam's starch serum (SS) agar, ${ }^{4}$ MacConkey's agar, and Todd-Hewitt broth with added gentamicin, $6 \mathrm{mg} / \mathrm{l}$, and nalidixic acid, $15 \mathrm{mg} / \mathrm{l}$, were used for isolation and viable count for group B streptococci; the count was expressed as $\log _{10}$ organisms $/ \mathrm{ml}$ of expressed swabs. The single-layered SS agar plates used in this study were made selective with added gentamicin, $6 \mathrm{mg} / \mathrm{l}$; the details of culture and identification techniques are as given in a previous study. ${ }^{2}$ All group B streptococcal isolates were serotyped at the Streptococcal Reference Laboratory, Colindale. The details of patients' ages, marital status, parity, and gestation period were also recorded.

Statistical analysis was by the $\chi^{2}$ test. 
Table 1 Viable counts and serotyping results of group B streptococcal isolates from multiple sites, and parity distributions in 21 carriers

\begin{tabular}{|c|c|c|c|c|c|}
\hline \multirow[t]{2}{*}{ Parity } & \multicolumn{4}{|c|}{ Group B count $\left(\log _{10}\right) / m l$ of expressed swab } & \multirow{2}{*}{$\begin{array}{l}\text { Respective serotype* } \\
n=62 \text { strains }\end{array}$} \\
\hline & $\begin{array}{l}\text { Perianal } \\
n=101\end{array}$ & $\begin{array}{l}\text { Perineol } \\
n=101\end{array}$ & $\begin{array}{l}\text { Vulval } \\
n=101\end{array}$ & $\begin{array}{l}\text { Low vaginal } \\
n=41\end{array}$ & \\
\hline \multicolumn{6}{|l|}{ Type II carriers ( 5 cases): } \\
\hline Primigravida & $4 \cdot 2 \dagger$ & $4 \cdot 0$ & 0 & - & $\mathbf{R}, \mathbf{I I} / \mathbf{R}$ \\
\hline, & $6 \cdot 7 \dagger$ & $5 \cdot 7$ & 0 & 0 & Both II/R \\
\hline$"$ & $6 \cdot 0 \dagger$ & $4 \cdot 0$ & $1 \cdot 9$ & $5 \cdot 4$ & II/Ic-p, NT, NT, II/Ic-p \\
\hline 3rd gravida & 0 & 0 & $2 \cdot 7 \dagger$ & - & II /R R \\
\hline,,$\quad$, & $2 \cdot 0 \dagger$ & $1 \cdot 7$ & $\mathbf{0}$ & 一 & II/Ic-p, Ic-p \\
\hline \multicolumn{6}{|l|}{ Type III carriers ( 3 cases): } \\
\hline 2nd gravida & $3 \cdot 7$ & $5 \cdot 0$ & $6.0+$ & - & III/R, III, III \\
\hline 3rd gravida & $4 \cdot 2$ & $1 \cdot 7$ & $4 \cdot 7 \dagger$ & 一 & $\mathbf{R}, \mathbf{R}, \mathbf{I I I} / \mathbf{R}$ \\
\hline ,, & $2 \cdot 2$ & $2 \cdot 0$ & $2 \cdot 7$ & $3 \cdot 0 \dagger$ & R, III, III, III/R \\
\hline \multicolumn{6}{|l|}{ Type I carriers (7 cases): } \\
\hline Primigravida & $6 \cdot 8$ & $6.9 \dagger$ & $5 \cdot 5$ & - & All Ia/R \\
\hline , & $2 \cdot 7$ & $3 \cdot 7 \dagger$ & $2 \cdot 7$ & - & All Ic \\
\hline , & $1 \cdot 6$ & $1 \cdot 8$ & $5 \cdot 7$ & $7 \cdot 2 \dagger$ & Ia, rest NT \\
\hline 2nd gravida & 0 & $2 \cdot 0$ & $3.0 \dagger$ & - & Both Ia \\
\hline,$\quad$, & $7 \cdot 4 \dagger$ & $4 \cdot 7$ & $3 \cdot 2$ & - & All Ic \\
\hline$", \quad$, & $1 \cdot 7$ & $1 \cdot 3$ & $2 \cdot 0+$ & - & All Ic \\
\hline 3rd gravida & 0 & 0 & $2 \cdot 0 \dagger$ & $1 \cdot 7$ & Both Ic-p \\
\hline \multicolumn{6}{|c|}{ Type $R, X$, and NT carriers (6 cases): } \\
\hline Primigravida & $5 \cdot 6 \dagger$ & $5 \cdot 5$ & $3 \cdot 5$ & 一 & All R \\
\hline , & $1 \cdot 7$ & $5 \cdot 4$ & $6 \cdot 7 \dagger$ & $5 \cdot 0$ & All $\mathbf{R}$ \\
\hline 2nd gravida & $3 \cdot 7$ & $5 \cdot 7 \dagger$ & $1 \cdot 8$ & 0 & All R \\
\hline Primigravida & 6.0 & $7 \cdot 3 \dagger$ & $6 \cdot 7$ & $6 \cdot 7$ & All X \\
\hline , & $1 \cdot 7$ & 1.9 & $5 \cdot 2 \dagger$ & $4 \cdot 8$ & All X \\
\hline , & $4 \cdot 7$ & $5 \cdot 7 \dagger$ & $4 \cdot 7$ & - & All NT \\
\hline $\begin{array}{l}\text { Total no. of positives ( } 21 \text { cases) } \\
(21 \%)\end{array}$ & $\begin{array}{l}18 \\
(18 \%)\end{array}$ & 18 & 18 & $\begin{array}{l}8 \\
(20 \%)\end{array}$ & \\
\hline
\end{tabular}

* Serotype variations only with R, NT, or with added Ic-p were not regarded as different strains.

tSite yielding highest colony count.

Ic-p - Ic-protein; NT = non-typable.

\section{Results}

Patients' ages ranged from 17 to 36 years with a mean of 26.4 years; 47 women were primigravidae with a mean age of 24 years; the mean parity (including abortions) of the patients was 1.78. Gestation periods ranged from 5 to 34 weeks.

Group B streptococci were isolated from 21 of the 101 pregnant women. The recovery rates from the four sites were very similar, and the colony counts did not differ significantly. In four out of five type II

Table 2 Group B streptococcal serotype distributions correlated with parity

\begin{tabular}{llllllll}
\hline Parity & \multicolumn{7}{l}{ Serotype $^{*}$ distributions } \\
\cline { 2 - 8 } & $I$ & $I I$ & $I I I$ & $R$ & $X$ & $N T$ & Total \\
\hline Primigravida & $3 \dagger$ & 3 & $0 \ddagger$ & 2 & 2 & 1 & 11 \\
2nd gravida & $3 \dagger$ & 0 & $1 \ddagger$ & 1 & 0 & 0 & 5 \\
3rd gravida & $1 \dagger$ & 2 & $2 \ddagger$ & 0 & 0 & 0 & 5 \\
Total & 7 & 5 & 3 & 3 & 2 & 1 & 21 \\
\hline
\end{tabular}

* For details of subtype distributions see Table 1.

NT $=$ non-typable.

$\dagger x^{2}=3 \cdot 5, \mathrm{P}>0.05$ (not significant).

$\mp x^{2}=3.0, \mathrm{P}>0.05$. carriers, the perianal swabs, and in each of the three type III carriers the vulval/vaginal (genital) swabs, yielded the highest counts of respective serotypes, but the differences were not statistically significant. Six out of seven type I strains, and all the six R, $X$, and non-typable (NT) strains, were isolated from the primigravidae and second gravidae women $\left(\chi^{2}=9.31, \mathrm{P}<0.005\right)$. There was a conspicuous absence of type III and III/R strains in the 11 positive primigravidae, but the numbers involved for individual serotypes in different parity groups are too small to be statistically significant (Tables 1 and 2).

Table 3 shows the influence of parity and gestation period on group B streptococcal viable counts and carriage rates. Nine out of 11 primigravidae had high colony counts with $\geqslant 10^{5}$ organisms $/ \mathrm{ml}$ of expressed swab, but all third gravidae had low counts $\left(\chi^{2}=9 \cdot 0\right.$, $P<0.005)$, and the second gravidae tended to have higher counts mostly in those more than 18 weeks' pregnant. The third gravidae had a significantly higher carriage rate $\left(\chi^{2}=5.8, \mathrm{P}<0.025\right)$ than the other parity groups, and women more than 18 weeks' pregnant had a carriage rate nearly double that of those who were less than 17 weeks' pregnant 
Table 3 Group B streptococcal viable counts and carriage rates correlated with gestation period and parity

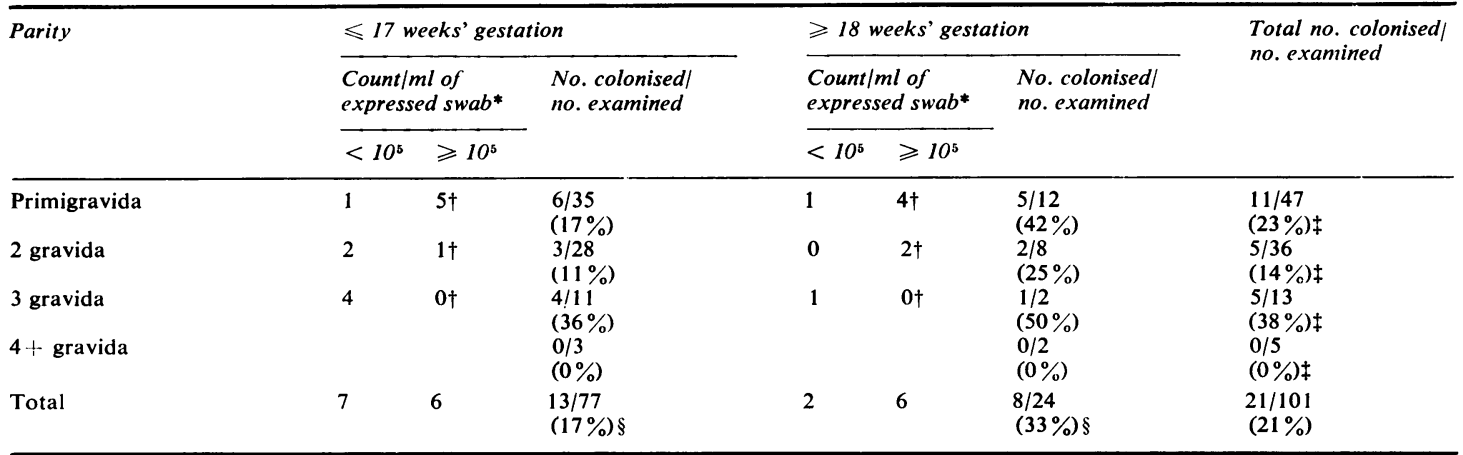

* Results expressed as no. of cases with indicated count (highest) at any of multiple sites.

$\dagger \chi^{2}=12.0, P<0.001$.

$\ddagger \chi^{2}=5.8, \mathrm{P}<0.025$.

$\S \chi^{2}=3 \cdot 0$, not significant

(P > 0.05, not significant). Five out of $10(50 \%)$ unmarried pregnant women, who constituted $10 \%$ of the cases studied, were colonised, a figure significantly higher than the $18 \%$ carriage rate in 91 married women $\left(\chi^{2}=5.75, \mathrm{P}<0.025\right)$.

\section{Discussion}

In this study the recovery rates of group B streptococci from the four sites were almost identical with an overall carriage rate of $21 \%$; this suggests that the women who are genital carriers are likely to be perineal and perianal carriers also. This is contrary to the findings of Kexel and Beck, ${ }^{5}$ who found decreasing rates of colonisation from anal to genital sites.

Five of 21 positive cases were type II carriers. In four of these the perianal swabs yielded the highest counts, and in three cases type II colonisations were localised to the perianal and perineal sites only (Table 1); in only two cases were the vulvovaginal sites involved. These findings suggest that the type II strains, which have been found to be the only group B streptococcal faecal isolates in adults, ${ }^{2}$ and the predominant isolates from rectal swabs, ${ }^{3}$ probably colonise the perianal region from a faecal source and then extend up to the perineum. None of the other serotypes was recovered exclusively from the perianal and/or perineal sites. In each of the three type III carriers the genital swabs yielded the highest counts, but the colonisations appeared to be more extensive, involving all the sites. It seems that type III strains, a predominant isolate in patients from sexually transmitted diseases clinics, ${ }^{6}$ colonise the vulvovaginal region primarily but are capable of spreading to perineal and perianal sites simultaneously. The type I strains had a scattered distribution of highest counts and did not conform to any pattern. These bacteria probably colonise the genitoperineo-perianal region secondarily from a pharyngeal source, ${ }^{7}$ or perhaps from the male urethra. ${ }^{8}$ $R, X$, and NT strains, which have recently been incriminated in acute neonatal disease (unpublished, PHLS Commun Dis Rep), behaved like type I in site, colony count, and parity distributions (Tables 1 and 2).

The findings of observable trends of group B serotypes among the different parity groups (Table 2 ) and significantly higher colony counts in primigravidae and second gravidae (Table 3) have important epidemiological implications. The reason for this parity specific group B serotype susceptibility is not clear. The primigravidae, none of whom (47 women) was a type III carrier, with a mean age of 24 years probably acquired type III immunity during their early adult life because type III antibody appears to be appreciably higher in young adults than in adolescents. ${ }^{9}$ During each pregnancy/puerperium the parturient woman acquires additional group B immunity to the type she harbours.

The findings of higher carriage rates among the third gravidae and unmarried pregnant women, and in those more than 18 weeks' pregnant (Table 3), are of interest, and these are contrary to the findings of others. Baker et al. ${ }^{10}$ and Beachler et al. ${ }^{11}$ probably examined highly selective groups of cases; moreover, they compared the data between primiparae and multiparous women, and between the second and third trimesters of pregnancy.

During 1978 at Whipps Cross Hospital 2781 deliveries were conducted and 2807 babies were born. During this period, assuming that $21 \%$ of the mothers were carriers, only three of the 589 at-risk neonates developed group B streptococcal disease. 
Two of these had acute disease: the first child had an early-onset type Ib septicaemia, and the second died of meningitis and septicaemia which developed within 48 hours of birth with a type Ia strain. Both the mothers were primigravidae and had an early rupture of the membranes, and their genito-perineoperianal swabs yielded group B streptococci type Ib $10^{5}$ to $10^{4}$, and type $\mathrm{Ia} 10^{7}$ to $10^{5} / \mathrm{ml}$ of expressed swabs, respectively. The third child, born to a second gravida, developed a late-onset asymptomatic group B bacteraemia, presumably secondary to umbilical catheter colonisation which cleared spontaneously.

These findings indicate that neonates born to primigravidae and second gravidae mothers who are likely to carry group B streptococci in high concentrations may be at risk of developing group B streptococcal neonatal disease. The size of the infective dose from mothers to neonates appears to be crucial for initiating an acute disease. Third gravidae women, who appear to carry group B in low concentrations, are probably capable of initiating a delayed infection only.

It appears that maternal parity plays a significant role in the epidemiology of group B neonatal disease. The patients examined in this study appeared to have fewer pregnancies (mean parity 1.78 ) and were relatively older (mean age 26.4 years) compared to United States figures (mean parity 2.0-2.6 and mean age 20.8 to 22.6 years). ${ }^{10}$ There may be a demographic variation with a larger population of pregnant women susceptible to type III organisms in the US accounting for the higher incidence of neonatal disease caused by type III strains from America. ${ }^{12}$

Although the mortality from acute group B neonatal infections is $60-75 \%, 13$ the very low attack rate $^{16}$ raises doubts as to the value of the routine screening of pregnant women and subsequent prophylaxis for carriers. A more rational approach would be to take specimens from all neonates at risk with complications of labour and from those of low birth weight, particularly those born to primigravidae and second gravidae. A quantitative count of group B streptococci on specimens from genital and perineal sites from these mothers is recommended, and a very high bacterial count should alert the clinician.
I thank Miss D Kayton, consultant obstetrician, and our consultant colleagues in the Maternity and Paediatric Units for permission to study their cases, and Miss A Rider and the nursing staff of the Maternity Unit for their co-operation. I am grateful to Dr T Chowdhury for obtaining specimens from the patients, to Dr MT Parker, Streptococcal Reference Laboratory, Colindale, for serotyping the group B streptococcal isolates, to Mr AR Constable, Institute of Urology, London, for the statistical analysis, and to Mrs M White for secretarial help.

\section{References}

${ }^{1}$ Baker CJ. Summary of the workshop on perinatal infections due to group B streptococcus. J Infect Dis 1977; 136:137-52.

2 Islam.AKMS,Thomas Elizabeth. Faecal carriage of group B streptococci. J Clin Pathol 1980;33:1006-8.

${ }^{3}$ Badri MS, Zawanch S, Cruz AC, et al. Rectal colonization with group B streptococcus: relation to vaginal colonization of pregnant women. J Infect Dis 1977; 135:308-12.

${ }^{4}$ Islam AKMS. Rapid recognition of group B streptococci. Lancet 1977 ; i:256-7.

${ }^{5}$ Kexel G, Beck KJ. Untersuchungen über die Häufigkeit der B Streptokokken im Wochenbett. Geburtshilfe Frauenheilkd 1965;25:1078-85.

${ }^{6}$ Finch RG, French GL, Phillips I. Group B streptococci in the female genital tract. Br Med $J$ 1976;1:1245-7.

${ }^{7}$ Christensen KK, Christensen P. Typing of group B streptococci from the throat and urogenital tract of females. Scand J Infect Dis 1978;10:209-12.

${ }^{8}$ Manuel FR, MacDonald SW, Embil JA. Prevalence of group B beta-haemolytic streptococci in male urethra. Scand J Infect Dis 1980;12:33-5.

${ }^{9}$ Baker CJ, Kasper DL. Immunological investigation of infants with septicaemia or meningitis due to group B streptococcus. J Infect Dis 1977;136:S98-104.

${ }^{10}$ Baker CJ, Barrett FF, Yow MD. The influence of advancing gestation on group B streptococcal colonization in pregnant women. Am J Obstet Gynecol 1975; $122: 820-3$.

${ }^{11}$ Beachler CW, Baker CJ, Kasper DL, Fleming DK, Webb BJ, Yow MD. Group B streptococcal colonization and antibody status in lower socioeconomic parturient women. Am J Obstet Gynecol 1979;133:171-3.

12 Wilkinson HW. Analysis of group B streptococcal types associated with disease in human infants and adults. $J$ Clin Microbiol 1978;7:176-9.

${ }^{13}$ Editorial. Group B streptococci in the newborn. Lancet $1977 ; \mathrm{i}: 520-1$.

Requests for reprints to: Dr AKMS Islam, Department of Microbiology, Whipps Cross Hospital, London E11 1NR. 